\title{
Pattern of paediatric congenital heart diseases.
}

1. FCPS (Pediatric Medicine) Associate Professor Pediatrics Sahara Medical College Narowal.

2. FCPS (Pediatric Medicine)

Assistant Professor Pediatrics Fatima Jinnah Medical University/ Sir Gangaram Hospital, Lahore.

3. FCPS (Pediatric Medicine) Assistant Professor Pediatric Medicine

Shalamar Medical and Dental College Lahore.

4. FCPS (Pediatric Medicine) Assistant Professor Pediatric Medicine

Pir Abdul Qadir Shah Jillani Institute of Medical Sciences, Gambat.

5. FCPS (Pediatric Medicine) Senior Registrar Pediatrics Sahara medical College Narowal.

6. FCPS (Pediatric Medicine) Fellow Pediatric Cardiology NICVD, Karachi.

Correspondence Address:

Dr. Fazal ur Rehman

Department of Pediatric Cardiology

NICVD, Karachi.

fazal171@gmail.com

Article received on:

01/03/2021

Accepted for publication:

4/06/202

\section{INTRODUCTION}

Heart disease among children contributes significantly to morbidity and mortality. Congenital heart disease (CHD) is a common type of heart diseases seen in children and adult population. ${ }^{1}$ CHD constitute major chunk of all types of major congenital malformation and estimated to affect between 2-3\% of neonates whereas prevalence of $\mathrm{CHD}$ is estimated to be between 3 to 10 per 1000 live-births globally. ${ }^{2,3}$ Around 40000 children are estimated to born in Pakistan with CHDs. ${ }^{4}$ Data from developing world has shown that burden of $\mathrm{CHDs}$ is rising due to escalation in etiological and risk factors. ${ }^{1}$ High risk of mortality is noted in CHD cases as most of $\mathrm{CHD}$ cases are representing late in cardiac healthcare setting while complications have already occurred adding further to overall mortality rates related to $\mathrm{CHDs} .^{5,6}$

Developing countries have significantly improved early identification as well as appropriated management for $\mathrm{CHD}$, thus, have seen significant decline in mortality rates. ${ }^{7,8}$ Recent data from Pakistan has shown ventricular septal defect (VSD) and tetralogy of fallot (TOF) to be the most common types of CHDs noted in $27 \%$ and $10.9 \%$ CHD cases. $^{9}$

The present study represents our experience about patterns of CHD types at a tertiary care hospital from Pakistan. Our findings will further add to what is known about the patterns of CHD and may help in formalizing proper strategies to decrease morbidity and mortality linked with it. The aim of this study was to find out pattern along with age and gender wise distribution of congenital heart disease (CHD) at a tertiary care hospital.

\section{MATERIAL \& METHODS}

This cross-sectional study was conducted at The Department of Pediatrics, Sughra Shafi 
Medical Complex, Narowal, from January 2019 to February 2020. During the study period, a total of 151 admitted children aged between 1 month to 15 years as confirmed case of CHD according to echocardiography were enrolled. Cases with acquired heart diseases were excluded. Approval from "Institutional Ethical Committee" was taken for this study. Informed consent was taken from parents or guardians of all study participants ensuring them the confidentiality of their data.

Gender, age categories, area of residence and types of CHDs were represented as frequency and percentages. Patients with different types of CHDs were distributed between both gender and different age categories. SPSS version 26.0 was used to handle and analyze all study related data.

\section{RESULTS}

During the study period, a total of 151 confirmed cases of CHD were enrolled. There were 82 $(54.3 \%)$ male and 69 (45.7\%) female representing a male to female ratio of 1.2:1. Most of the cases were aged less than 1 year. There were $118(78.1 \%)$ children below 1 year of age while $22(14.6 \%)$ between 1 to 5 years of age and 11 $(7.3 \%)$ above 5 years of age. There were 102 $(67.5 \%)$ patients who belonged to rural areas of residence while remaining 49 (32.5\%) were from urban areas.

VSD and ASD were the commonest types of acyanotic heart lesions in 41 (27.2\%) and 29 $(19.2 \%)$ cases respectively whereas TOF was the most frequency type of cyanotic heart lesion in $23(15.2 \%)$ cases. Table-I is showing frequency of different CHD types with respect to gender distribution while Table-II is showing distribution of age with respect to different types of CHDs.

\begin{tabular}{|l|c|c|c|}
\hline \multicolumn{1}{|c|}{ CHD Types } & Number & \multicolumn{2}{c|}{ Gender } \\
\hline Ventricular Septal Defect (VSD) & 41 & $24(58.5 \%)$ & Female (\%) \\
\hline Atrial Septal Defect (ASD) & 29 & $16(55.2 \%)$ & $13(44.5 \%)$ \\
\hline Tetralogy of Fallot (TOF) & 23 & $11(47.8 \%)$ & $12(52.2 \%)$ \\
\hline Patent Ductus Arteriosus (PDA) & 17 & $9(52.9 \%)$ & $8(47.1 \%)$ \\
\hline Transposition of the Great Arteries (TGA) with VSD with pulmonary stenosis (PS) & 7 & $3(42.9 \%)$ & $4(57.1 \%)$ \\
\hline TGA with VSD with Pulmonary Hypertension (PH) & 6 & $3(50.0 \%)$ & $3(50.0 \%)$ \\
\hline Complete Atrioventricular Septal Defect (AVSD) & 6 & $3(50.0 \%)$ & $3(50.0 \%)$ \\
\hline Pulmonary atresia & 3 & $1(33.3 \%)$ & $2(66.7 \%)$ \\
\hline Tricuspid atresia & 3 & $2(66.7 \%)$ & $1(33.3 \%)$ \\
\hline Complex Heart Disease & 5 & $3(60.0 \%)$ & $2(40.0 \%)$ \\
\hline Others & 11 & $7(63.6 \%)$ & $4(36.4 \%)$ \\
\hline Total & 151 & $82(54.3 \%)$ & $69(45.7 \%)$ \\
\hline
\end{tabular}

Table-I. Distribution of Gender with regards to CHDs. $(n=151)$

\begin{tabular}{|l|c|c|c|c|}
\hline \multicolumn{1}{|c|}{ CHD Types } & Number & \multicolumn{3}{c|}{ Age (years) } \\
\cline { 2 - 5 } & & $<1(\%)$ & $\mathbf{1 - 5}(\%)$ & $>\mathbf{5}(\%)$ \\
\hline Ventricular Septal Defect (VSD) & 41 & $36(87.8 \%)$ & $3(7.3 \%)$ & $2(4.9 \%)$ \\
\hline Atrial Septal Defect (ASD) & 29 & $26(89.7 \%)$ & $2(6.9 \%)$ & $1(3.4 \%)$ \\
\hline Tetralogy of Fallot (TOF) & 23 & $18(78.3 \%)$ & $4(17.4 \%)$ & $1(4.3 \%)$ \\
\hline Patent Ductus Arteriosus (PDA) & 17 & $11(64.7 \%)$ & $4(23.5 \%)$ & $2(11.8 \%)$ \\
\hline $\begin{array}{l}\text { Transposition of the Great Arteries (TGA) with VSD with pulmonary } \\
\text { stenosis (PS) }\end{array}$ & 7 & $6(85.7 \%)$ & $1(14.3 \%)$ & 0 \\
\hline TGA with VSD with Pulmonary Hypertension (PH) & 6 & $5(83.3 \%)$ & $1(16.7 \%)$ & 0 \\
\hline Complete Atrioventricular Septal Defect (AVSD) & 6 & $4(66.7 \%)$ & $1(16.7 \%)$ & $1(16.7 \%)$ \\
\hline Pulmonary atresia & 3 & $1(33.3 \%)$ & $1(33.3 \%)$ & $1(33.3 \%)$ \\
\hline Tricuspid atresia & 3 & $2(66.7 \%)$ & $1(33.3 \%)$ & 0 \\
\hline Complex Heart Disease & 5 & $3(60.0 \%)$ & $1(20.0 \%)$ & $1(20.0 \%)$ \\
\hline Others & 11 & $6(54.5 \%)$ & $3(27.3 \%)$ & $2(18.2 \%)$ \\
\hline Total & 151 & 118 & 22 & 11 \\
\hline
\end{tabular}

Table-II. Distribution of age with regards to CHDs. $(n=151)$ 


\section{DISCUSSION}

In the last few decades, compared to developing countries, developed world has made significant advancements in medical sciences that have helped timely identification and management of patients living with cardiac diseases. ${ }^{1}$ On the other hand, in a country like Pakistan, it is still very challenging to timely identify and manage CHDs in children. Lots need to be done in Pakistan to estimate and frame management strategies for children living with $\mathrm{CHDs}$.

The CHDs can be simple defects presenting without any symptoms while complex defects can represent with serious life threatening conditions. ${ }^{10}$ In the present study, $78.1 \%$ children with confirmed CHDs were below 1 year of age. Age of diagnosis of CHDs among children is variable in different parts of the world as multiple factors contribute to this variation. ${ }^{11}$ Data from India found $69.7 \%$ of their CHD cases to be within 1 year of age. ${ }^{12}$ Shah et al showed $55.5 \%$ of their study cases to be below 1 year of age. ${ }^{13}$ Local study done by Khan et al recorded $71 \%$ of CHD cases to be below 1 year of age. ${ }^{14}$ As CHD is known to be the most frequent types of major congenital malformations, high rates of mortality are associated with CHDs in $1^{\text {st }}$ year of life. ${ }^{9}$ Quite a few $\mathrm{CHD}$ cases are not detected timely as many of these present asymptomatically. ${ }^{10}$

We noted $54.3 \%$ of the children to be male. Mohammad N et al ${ }^{15}$ in a local study found $55.3 \%$ of their cases with CHDs to be male which is quite close to which we found. Regional data from India also elaborates males to form majority of $\mathrm{CHD}$ cases $(66 \%) .{ }^{12}$

In this study, VSD and ASD were noted to be the most frequent types of acyanotic heart lesions in $41(27.2 \%)$ and $29(19.2 \%)$ cases respectively whereas TOF was the most frequency type of cyanotic heart lesion in 23 (15.2\%) cases. Study from Karachi ${ }^{16}$ also found VSD to be the most common type of acyanotic heart lesion while TOF was the most frequent cyanotic heart lesion. Another local study also showed VSD, TOF and ASD to be the most frequent types of CHDs noted. ${ }^{17}$ Aman $\mathrm{W}$ et al also observed similar findings. ${ }^{18}$ Sehar T et al found VSD as the most frequent congenital heart lesion seen in 18\% of their cases while PDA was the $2^{\text {nd }}$ most frequent heart lesion. ${ }^{9}$ Data from India recorded VSD to be the commonest type of $\mathrm{CHD}$ seen in $21.3 \%$ of their cases whereas ASD was the $2^{\text {nd }}$ most common heartlesion seen in $18.9 \%$ cases. ${ }^{19}$ Worldwide, VSD is known to be the commonest type of acyanotic heart lesion seen in $25-30 \%$ of CHD patients. ${ }^{20}$ Differences in patterns of CHD types could be credited to differences in diagnostic modalities as well as variation in healthcare standards whereas genetic and various environmental factors are also responsible for these variations. ${ }^{1,11}$

Our study had some limitations as well. No management or follow up data was recorded in the present set of patients. Further studies are required to record follow up and pre-school/ school data which is thought to highlight some important clinical and social aspects of CHDs in our population.

\section{CONCLUSION}

VSD followed by ASD and TOF were noted to be the most frequent types of CHD. As most CHD cases are reporting with age less than 1 year, there is a need to establish more cardiac surgery centers in Pakistan.

\section{ACKNOWLEDGEMENT}

The authors are thankful to Mr. Muhammad Aamir (Research Consultant, Bahawalpur) for his volunteer assistance in statistical analysis of this research.

Copyright $\odot 04$ Jun, 2021.

\section{REFERENCES}

1. Wu W, He J, Shao X. Incidence and mortality trend of congenital heart disease at the global, regional, and national level, 1990-2017. Medicine (Baltimore). 2020; 99(23):e20593.

2. Latal B. Neurodevelopmental outcomes of the child with congenital heart disease. Clin Perinatol. 2016; 43:173-185.

3. Rizvi SF, Mustafa G, Kundi A, Khan MA. Prevalence of congenital heart disease in rural communities of Pakistan. J Ayub Med Coll Abbottabad. 2015; 27(1):124-127. 
4. Farooqui R, Haroon UF, Niazi A, Rehan N, Butt TK, Niazi $M$. Congenital heart diseases in neonates. J Rawal Med Coll. 2010; 14:31-32.

5. Sun P, Ding G, Zhang M, He S, Gao Y, Wang J. Prevalence of congenital heart disease among infants from 2012 to 2014 in Langfang, China. Chin Med J (Engl). 2017; 130(9):1069-1073.

6. Bertoletti J, Marx GC, Hattge SP, Pellanda LC. Quality of life and congenital heart disease in childhood and adolescence. Arq Bras Cardiol. 2014; 102(2):192-198.

7. Jortveit J, Øyen N, Leirgul E, Fomina T, Tell GS, Vollset $\mathrm{SE}$, et al. Trends in mortality of congenital heart defects. Congenit Heart Dis. 2016; 11(2):160-8.

8. Mandalenakis Z, Rosengren A, Skoglund K, Lappas $G$, Eriksson P, Dellborg M. Survivorship in children and young adults with congenital heart disease in Sweden. JAMA Intern Med. 2017; 177(2):224-230.

9. Sehar T, Sheikh AM, Kanwal M. To identify pattern of congenital heart diseases in a newly developed tertiary care unit. Pak Armed Forces Med J. 2019; 69(4):831-836.

10. Bano S, Akhtar S, Khan U. Pediatric congenital heart diseases: Patterns of presentation to the emergency department of a tertiary care hospital. Pak J Med Sci. 2020; 36(3):333-337.

11. Knowles RL, Ridout D, Crowe S, Bull C, Wray J, Tregay $\mathrm{J}$, et al. Ethnic and socioeconomic variation in incidence of congenital heart defects. Arch Dis Child. 2017; 102(6):496-502.
12. Karthiga S, Pathak S, Lazarus M. Clinical and anthropometric profile of congenital heart disease in children admitted in pediatric ward. Int J Scient Stu. 2017; 5(5):112-117.

13. Shah GS, Singh MK, Pandey TR, Kalakheti BK, Bhandari GP. Incidence of congenital heart disease in tertiary care hospital. Kathmandu Univ Med J. 2008; 6:33-6.

14. Khan I, Muhammad A, Muhammad T. Pattern of congenital heart disease at lady reading hospital Peshawar. Gomel J Med Sci. 2011; 9:174-177.

15. Mohammad N, Shaikh S, Memona S, Das H. Spectrum of heart disease in children under 5 years of age at Liaquat University Hospital, Hyderabad, Pakistan. Indian Heart J. 2014; 66:145-149.

16. Hassan I, Haleem AA, Bhutta ZA. Profile and risk factors for congenital heart disease. J Pak Med Assoc. $1997 ;$ 47(3):78-81.

17. Burki MK, Babar GS. Prevalence and pattern of congenital heart disease in Hazara. J Ayub Med Coll Abbottabad. 2001; 13(4):16-18.

18. Aman W, Sherin A, Hafizullah M. Frequency of congenital heart diseases in patients under the age of twelve years at Lady Reading Hospital Peshawar. JPMI. 2006; 9(1):64-69.

19. Kapoor R, Gupta S. Prevalence of congenital heart disease, Kanpur, India. Indian Pediatr. 2008; 45:309311.

20. Behrman RE, Kliegman RM, Jenson HB. Nelson text book of pediatrics: 17th ed. 2004:1499-1502.

\begin{tabular}{|c|c|c|c|}
\hline \multicolumn{4}{|c|}{ AUTHORSHIP AND CONTRIBUTION DECLARATION } \\
\hline No. & Author(s) Full Name & Contribution to the paper & Author(s) Signature \\
\hline 1 & $\begin{array}{l}\text { Khurram Shahnawaz } \\
\text { Farhan Zahoor }\end{array}$ & $\begin{array}{l}\text { Data collection, Final } \\
\text { approval. } \\
\text { Introduction, Proof reading. }\end{array}$ & \\
\hline 3 & Bushra Madni & $\begin{array}{l}\text { Literature review, } \\
\text { Methodology. }\end{array}$ & Bushna Madri \\
\hline 4 & Muhammad Imran & Data analysis, Discussion. & 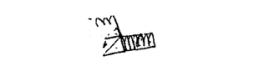 \\
\hline 5 & Muhammad Naveed & $\begin{array}{l}\text { Literature review, Data } \\
\text { collection. }\end{array}$ & lisule \\
\hline 6 & & Drafting, References. & 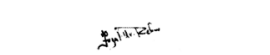 \\
\hline
\end{tabular}

